\title{
ESTUDOS NO EXTERIOR E MEDIAÇÃO DE MODELOS INSTITUCIONAIS: OCASO DOS JURISTAS BRASILEIROS ${ }^{1}$
}

\author{
Fabiano Engelmann
}

\begin{abstract}
RESUMO
O presente texto constitui uma análise do perfil dos estudos no exterior dos professores de mestrado e doutorado em Direito no Brasil, a partir das informações fornecidas por eles nos currículos registrados na Plataforma Lattes, do Conselho Nacional de Desenvolvimento Científico e Tecnológico (CNPq), em 2006. Esses dados são analisados no contexto de uma discussão sobre os efeitos da internacionalização das perícias de gestão do Estado e dos usos das "Ciências Sociais Aplicadas", já que a utilização de tais perícias está relacionada às estratégias mobilizadas pelos agentes nas disputas pelas posições de poder e pela definição do sentido de "Estado", "política" e "justiça". Assim, pode-se elaborar hipóteses sobre a relação entre a circulação internacional de juristas brasileiros e os movimentos de importação e exportação de modelos institucionais, bem como suas repercussões no espaço jurídico e político nacionais. As reconversões de agentes - até então dedicados principalmente ao "mundo operacional" - em direção à carreira acadêmica e à produção intelectual, por meio dos investimentos em titulação de doutorado e em estudos no exterior, podem ser analisadas em estreita correspondência com a demanda pela refundamentação e com a internacionalização dos conhecimentos relacionados ao Estado e à gestão das instituições políticas e jurídicas. Da mesma forma, esse processo, no caso dos juristas, contempla a fundamentação intelectual da resistência aos modelos institucionais que apontam para o enfraquecimento dos pressupostos do Estado-nação.
\end{abstract}

PALAVRAS-CHAVE: estudos no exterior; mediação institucional; espaço jurídico; elites jurídicas; circulação internacional de elites.

\section{INTRODUÇÃO}

A expansão dos cursos de pós-graduação nas áreas de "Ciências Sociais Aplicadas”, no Brasil, a partir da segunda metade da década de 1990, põe em pauta o efeito desse processo nos campos profissionais em que repercutem tais perícias no uso operacional das Ciências Sociais. Nesse sentido, a análise das bases sociais da diferenciação desse espaço de produção de tecnologias institucionais - e de gestão do Estado - é um dos pontos de partida para a apreensão dos padrões de utilização desses conhecimentos em seus res-

\footnotetext{
${ }^{1}$ Uma versão deste texto foi apresentada originalmente no seminário Circulation Internationale des universitaires et recomposiont des champs intelectueles, no âmbito do Centre de Recherches sur le Brésil Contemporain (CRBC), da École des Hautes Etudes en Sciences Sociales (EHESS), em novembro de 2006. Os resultados apresentados originaram-se de pesquisa apoiada pelo Conselho Nacional de Desenvolvimento Científico e Tecnológico (CNPq).
}

pectivos campos profissionais, bem como na esfera do poder político. Os usos de tais perícias ${ }^{2}$ estão relacionados às estratégias mobilizadas pelos agentes nas disputas pelas posições de poder $\mathrm{e}$ pela definição do sentido de "Estado”, "política” e "justiça".

As reconversões de agentes - até então dedicados principalmente ao "mundo operacional" em direção à carreira acadêmica e à produção intelectual, através dos investimentos em titulação de Doutorado e estudos no exterior, podem ser analisadas em estreita correspondência com a demanda pela refundamentação e com a internacionalização dos conhecimentos relacionados ao Estado e à gestão das instituições políticas e jurídicas. Da mesma forma, esse processo, no

2 Para um detalhamento maior sobre o uso de "perícias” e do conhecimento científico como recurso estratégico na luta política, ver Hamman (2002). 
caso dos juristas, contempla a fundamentação intelectual da resistência aos modelos institucionais que apontam para o enfraquecimento dos pressupostos do Estado-nação.

Nesses termos, o presente trabalho analisa uma parte específica desse processo, focalizando o perfil geral dos estudos no exterior realizados pelos juristas, cuja posição de mediadores de modelos institucionais é constantemente reelaborada. Uma das dimensões da redefinição dessa posição está justamente nos estudos no exterior, que possibilitam a inserção em um espaço internacionalizado de importação e exportação de bens simbólicos. Da mesma forma, a circulação permite a acumulação de um capital internacional reconvertido na ocupação de posições em câmaras de comércio e arbitragem inter-nações, tribunais internacionais, redes de organizações não governamentais de promoção de Direitos e redes de cooperação acadêmica.

Visando uma apreensão mais nítida das bases do processo de expansão e dos efeitos da pósgraduação em Direito e sua relação com a importação de modelos institucionais, parte-se da exploração de um conjunto de currículos de docentes de Mestrado e Doutorado na área, registrados na Plataforma Lattes, do CNPq. Essa exploração tem como objetivo obter informações gerais sobre os estudos no exterior e indicações acerca de percursos profissionais, políticos e intelectuais ${ }^{3}$. A partir dos dados produzidos nessas bases, são propostas hipóteses para a relação da expansão dos cursos de pós-graduação e dos estudos no exterior com os fenômenos de reestruturação do espaço jurídico e da relação dos juristas com o espaço político, durante as décadas de 1990 e 2000, no Brasil.

\section{ELEMENTOS PARA A ABORDAGEM DA CIRCULAÇÃO INTERNACIONAL DE MO- DELOS INSTITUCIONAIS}

Adota-se como referencial geral para a construção das categorias de análise e dos dados empíricos do presente trabalho, a noção de cam-

\footnotetext{
3 Um banco de dados com resumos das teses defendidas sobre o Brasil, na França, em Ciências Humanas e Ciências Sociais Aplicadas, pode ser encontrado na publicação Cahiers du Brésil Contemporain, n. hors série e n. 45-46, de 2000 e 2001, respectivamente; o banco encontra-se disponível, também, em CRBC (2007).
}

po jurídico, desenvolvida por Bourdieu. Conforme o autor: "As práticas e os discursos jurídicos são, com efeito, o produto do funcionamento de um campo cuja lógica específica está duplamente determinada: por um lado, pelas relações de força específicas que lhe conferem a sua estrutura e que orientam as lutas de concorrência, ou mais precisamente, os conflitos de competência que nele têm lugar e, por outro lado, pela lógica interna das obras jurídicas que delimitam em cada momento o espaço dos possíveis e, deste modo, o universo das soluções propriamente jurídicas” (BOURDIEU, 1986, p. 3-4).

A abordagem do espaço dos juristas nessa perspectiva, leva a considerar-se, como dimensão de análise fundamental, os mecanismos de recrutamento para as diversas carreiras - socialmente instituídas por ritos, símbolos e garantias legitimadas pela força do Estado - e as tomadas de posição doutrinárias por parte dos juristas frente ao Direito. Para o caso especifico do presente trabalho, o recurso da passagem por estudos no exterior no processo de construção das posições doutrinárias - as quais, em alguma medida, dão sentido às instituições - é fundamental. Como assinala Dezalay (1999, p. 295), partindo dos pressupostos analíticos desenvolvidos por Bourdieu, "a visão dos juristas vai além dos temas civis e abrange as próprias instituições do Estado, cuja atribuição não é apenas a de proporcionar melhor garantia na preservação do quase-monopólio dos conflitos, mas também a de responder pela formação das relações sociais”.

A apreensão dos condicionantes da "visão dos juristas” e de sua relação com a construção do Estado envolve o mapeamento dos principais pólos em concorrência - os quais estruturam-se em função das hierarquias que envolvem os saberes disciplinares e as carreiras, mais ou menos prestigiadas - e da relação da trajetória e inserção social, política e acadêmica dos agentes com os mais diversos usos do Direito e da "tradição jurídica”. Os pólos em concorrência aparecem nas disputas pelo sentido das definições de "justiça" e "Direito", formalizadas na doutrina jurídica. O estudo do espaço de produção doutrinário e de sua crescente internacionalização - um dos objetos centrais das lutas pelo monopólio de dizer o Direito - é fundamental para a compreensão dos princípios de estruturação dessas disputas. Nessa análise, é necessário pôr em questão as relações 
dos produtores do Direito com os diversos grupos sociais aos quais estão vinculados e com os "interesses sociais que estes agentes traduzem na forma do Direito” (DEZALAY, 1993, p. 232).

Em geral, a problemática da circulação internacional de idéias tem sido objeto de trabalhos que abordam temas como a repercussão das viagens de estudos e da circulação entre sociedades imperiais (cf. CHARLE, 2001) e a definição das lutas no campo intelectual, entre sociedades centrais (cf. BOURDIEU, 2002). Em dinâmicas importadoras de instituições, como nos casos brasileiro e latinoamericano, a circulação internacional das elites intelectuais - e sua afirmação como importadora de instituições - assume um papel-chave na definição e construção da dimensão nacional dos modelos institucionais. Nesse sentido, relaciona-se a diversas estratégias de disputa entre os segmentos da elite política e intelectual (cf. BADIE, 1992).

Em trabalho sobre a América Latina, Dezalay e Garth (2002) enfocam o papel da circulação internacional das tecnologias institucionais e das definições do Direito, em que se firmam um pólo produtor (Europa e, mais recentemente, Estados Unidos) e um pólo importador (Brasil e América Latina). Essa circulação de modelos e problemáticas envolve sua assimilação e uso para a legitimação de determinados grupos dirigentes nacionais. Tal ocorre, principalmente, no âmbito dos cursos de pós-graduação e na aliança de grupos de economistas e juristas com elites não-tradicionais desses países, opondo novos princípios de legitimação no espaço do poder ${ }^{4}$.

Para uma melhor verificação da hipótese dos autores quanto à circulação internacional dos juristas brasileiros, há necessidade de incluir indicadores que possibilitem um maior detalhamento das relações estabelecidas entre os segmentos importadores e o uso destes produtos para sua legitimação frente ao mundo acadêmico e ao mundo da esfera política e jurídica. Essas estratégias de importação podem envolver tanto a reconversão de setores tradicionais, mas com posições sociais ameaçadas, quanto a legitimação de novos grupos de juristas. Nesse sentido, a problemática específica do que Badie e Hermet denominam uma "di-

\footnotetext{
4 Um panorama amplo da relação entre estudos no exterior, para o caso brasileiro, e sua repercussão na conformação de diversos campos profissionais pode ser encontrado em Almeida (2004).
}

nâmica órfã" - ou seja, "Estados que se caracterizam pela importação de modelos de instituições que não são produtos de sua história social e política” (BADIE \& HERMET, 1993, p. 180) - está na base das principais diferenças em relação à estruturação das instituições em países periféricos, principalmente quanto aos efeitos de hibridização e justaposição entre as instituições importadas e os respectivos padrões das relações com estes produtos.

De acordo com Badie, tais bens simbólicos podem servir a diversas estratégias de legitimação realizadas pelos diversos segmentos das elites políticas e intelectuais: "Freqüentemente concebida como arma de poder, a importação de modelos ocidentais serve tanto para os projetos conservadores como para os projetos revolucionários; alvo da maior parte dos movimentos contestatórios, ela se infiltra até nas suas temáticas e suas práticas políticas cotidianas; instrumento de ação e de governo, ela serve largamente para o jogo das elites intelectuais, em qualquer corrente de pensamento ou de linguagem e em qualquer ideologia (BADIE, 1992, p. 127).

Assim, a caracterização do Brasil como um "país importador" 5 de modelos institucionais remete ao enfoque da presente pesquisa, que visa produzir indicadores que permitam estabelecer a relação entre a circulação internacional, a posição social, intelectual e política e as diversas esferas em que os agentes e grupos apropriam-se e reconvertem tais produtos para utilizá-los nas lutas entre as principais posições em concorrência no espaço jurídico e político, principalmente naquelas concernentes à construção ou "reforma" de instituições estatais. Um dos caminhos para a explicitação desse espaço de importação de instituições é a análise dos padrões de formação acadêmica no exterior e sua relação com o espaço das "práticas" dos juristas.

Nesses termos, trata-se de compreender, como pontua Dezalay, como os juristas que "durante séculos atrelaram seu próprio destino ao Estado nacional, se amoldaram à abertura de fronteiras que acompanhou a colocação em questão de um certo número de prerrogativas do Estado"

5 Maior detalhamento sobre os diversos caminhos metodológicos para o estudo comparado de instituições que conformam o campo do debate epistemológico da "política comparada” pode ser encontrado em Thiriot (2004). 
(DEZALAY, 1999, p. 295). As possibilidades de reconversão do conhecimento elaborado no âmbito dos cursos de pós-graduação seguem o ritmo da recomposição do campo das “práticas” dos juristas, ao longo da década de 1990, no Brasil ${ }^{6}$. A diversificação das carreiras de Estado, com a afirmação de instituições como o Ministério Público, estadual e federal, e como a magistratura federal, com relativa autonomia em relação ao mundo da política, também merece ser analisada como espaço de reconversão do conhecimento e dos títulos obtidos no exterior.

Em síntese, pode-se tomar como hipótese geral que a expansão dos cursos de Mestrado e Doutorado em Direito, no Brasil, e dos estudos no exterior, realizados com incentivos de diversas modalidades de bolsa, está, em alguma medida, relacionada às redefinições do universo dos "operadores do Direito", as quais potencializam um efeito de recomposição do campo jurídico por meio de fundamentações para novas espécies de "Direitos" e definições de "justiça”, assim como para a re-elaboração de saberes disciplinares e modelos internos ao campo jurídico. Tal fenômeno, portanto, posiciona determinados segmentos de juristas, docentes de pós-graduação, consultores - os quais transitam em redes internacionais acadêmicas, organizações não-governamentais (ONGs) ou comissões de organismos internacionais - como mediadores de modelos institucionais.

\section{O PADRÃO HISTÓRICO DE FORMAÇÃO DOS JURISTAS NO CASO BRASILEIRO}

Desde o final do período colonial, os juristas brasileiros posicionam-se como mediadores de instituições políticas e jurídicas, principalmente por meio dos estudos na Universidade de Coimbra e da posterior ocupação de postos de poder na administração imperial 7 . A partir de 1827, os estudos em Coimbra são substituídos pela formação

\footnotetext{
6 Um caso exemplar disso é o do crescente uso do Judiciário como recurso para fazer reconhecer Direitos por meio da tradução de causas políticas em causas jurídicas; nesse sentido, ver Engelmann (2006b).

7 As escolas de Direito constituídas no Brasil, a partir do modelo de Coimbra, assim como as práticas políticas dos bacharéis constituíram-se num saber-fazer político específico, baseado na retórica, na conciliação política e na importação de modelos europeus, que originou a expressão "bacharelismo", conforme indicam os estudos de Adorno (1988), Carvalho (1996) e Gauer (2001).
}

nas academias de São Paulo e Olinda e, a partir da proclamação da República em 1889, nas faculdades de Direito das províncias (cf. VENÂNCIO FILHO, 1977). Com a fundação das faculdades provinciais, ocorre um processo de endogeneização da formação jurídica e um relativo bloqueamento dos estudos no exterior.

Em grande medida, esse processo pode ser atribuído a uma enorme oferta de postos públicos na burocracia e à especialização do campo judicial, a partir da década de 1930, em detrimento da institucionalização da carreira acadêmica, no quadro das faculdades de Direito. Nesse cenário, as apostas dos juristas dirigem-se, antes, para a ocupação de postos nas carreiras burocráticas e na esfera da política. A proliferação das faculdades, que ocorre particularmente a partir da década de 1960, não se faz acompanhar, até a década de 1990, da institucionalização de cursos de Mestrado e Doutorado e, tampouco, da pesquisa acadêmi$\mathrm{Ca}^{8}$.

No âmbito da advocacia, tem-se um efeito de internacionalização durante o período do regime militar (1964-1985), que favorece o militantismo judicial a favor dos presos políticos, por meio da inserção em redes internacionais de promoção dos direitos humanos e de denúncias a organismos internacionais, particularmente por meio de ONGs especializadas ${ }^{9}$. Outro caminho de internacionalização do conhecimento jurídico pode ser relacionado à ampliação dos negócios internacionais e à prática da arbitragem comercial internacional. Esta última modalidade, inspirada na matriz americana, repercute na redefinição de formas de mediação de litígios e na formatação de sociedades de advogados, aparecendo de forma mais intensa a partir do aprofundamento da internacionalização da economia brasileira, na década de 1990, mas com pouco impacto no espaço das definições institucionais de Justiça e Estado, se comparada à matriz americana ${ }^{10}$.

8 Para maior detalhamento sobre a expansão do ensino universitário de pós-graduação em Direito e sua legitimação frente ao universo das “carreiras práticas”, ver Engelmann (2006a; 2007) e Sarat e Scheingold (2006).

9 Sobre o ativismo judicial e as redes internacionais de ativistas de direitos humanos, no Brasil e América Latina, ver Meili (2001) e Dezalay (2002).

10 Para um maior detalhamento sobre a relação entre a internacionalização da economia e a reestruturação da ordem jurídica americana, ver Dezalay (1992). 
Na magistratura e no Ministério Público, os perfis profissionais historicamente indicam uma fraca presença de estudos no exterior, em grande medida, devido ao fato de que os investimentos realizados prioritariamente no conhecimento técnico para concursos públicos e na consolidação do exercício funcional - excluem estadas longas no exterior, ao menos até a década de 1990. Entretanto, essa realidade também tende a modificar-se, com a reorganização institucional dessas carreiras, após a promulgação da Constituição de 1988, que representa um novo marco institucional para as carreiras jurídicas de Estado. Nesse período, aumentam os programas de incentivos para a realização de cursos de pós-graduação e ocorre a progressiva institucionalização de escolas superiores preparatórias para concursos públicos, geridas pelas próprias associações de juízes e promotores.

\section{O PERFIL DOS ESTUDOS REALIZADOS PELOS JURISTAS NO EXTERIOR}

A população de docentes atuando nas pós-graduações em Direito stricto sensu, no Brasil, em 2006, pode ser estimada em cerca de 650. Até 1990, havia 15 cursos de Mestrado e quatro de Doutorado. No segundo semestre de 2006, contabilizava-se 58 mestrados e 16 doutorados ${ }^{11}$. A grande mobilidade e a multiposicionalidade da população analisada - com diversos casos presentes em mais de uma instituição - e a presença de docentes de outras áreas do conhecimento impedem o estabelecimento de uma grandeza exata sobre a população. Do universo de 650 , foram analisados 410 currículos representativos de instituições situadas nas cinco regiões do país. Chegou-se a esse número, que representa $65 \%$ do total estimado, por meio de pesquisa na Plataforma Lattes, a partir das listas de professores constantes nos sítios institucionais ou no próprio sítio da Coordenação de Aperfeiçoamento de Pessoal de Nível Superior (Capes). Nessa busca, observou-se que diversos professores não possuíam registros na Plataforma, ou o possuíam de forma incompleta, o que limitou a agregação de informações e a produção de dados válidos para comparação. 11 Informações retiradas do sítio da Coordenação de Aper-
feiçoamento de Pessoal de Nível Superior (Capes) e
complementadas com informações dos programas de pós-
graduação.
Dos 410 currículos obtidos, chegou-se a 123 com algum tipo de passagem no exterior. A partir dessa população, foram agrupadas informações em nove categorias: ano de conclusão dos estudos no exterior; país escolhido; modalidade de financiamento; instituição no exterior; tema de estudo no exterior; modalidade de curso realizado no exterior; instituição universitária de atuação no Brasil; unidade da federação em que atua; e atuação extra-acadêmica no Brasil.

QUADRO 1 - PERFIL DOS ESTUDOS DE PÓS-
GRADUAÇÃO DA POPULAÇÃO
PESQUISADA
\begin{tabular}{|l|c|c|}
\hline LUGAR DOS ESTUDOS & $\boldsymbol{N}$. & $\%$ \\
\hline Brasil & 287 & 70 \\
Exterior & 123 & 30 \\
Total & 410 & 100 \\
\hline
\end{tabular}

FONTE: o autor, a partir de Brasil. Conselho Nacional de Desenvolvimento Científico e Tecnológico (2006).

No quadro, observa-se que o conjunto que apresenta alguma modalidade de estudo de pósgraduação no exterior constitui $30 \%$ dos casos. Há, portanto, um padrão de endogeneização na formação de pós-graduação em Direito. Foram contabilizados não somente os cursos de Doutorado, mas também estadas mais curtas, como de especialização ou aperfeiçoamento, visando detectar as peculiaridades dos estudos no estrangeiro. Considerando-se apenas os cursos de Doutorado, a freqüência torna-se ainda menor. Como diversos juristas estudaram em mais de um país, foi contabilizada cada passagem no exterior como um caso específico.

Uma das hipóteses que podem ser levantadas em relação a esta endogeneização é a recente expansão dos programas de pós-graduação e a ausência de uma tradição internacional entre as modalidades dominantes de carreira jurídica. Com a emergência da carreira acadêmica, como aposta de ascensão social entre os juristas (cf. ENGELMANN, 2006a), e o aumento dos incentivos, com o incremento da concessão de bolsas, os estudos no exterior passaram a apresentar maior freqüência.

No quadro abaixo, agrupando-se as modalidades de financiamento, é possível detectar a importância da existência de programas de bolsas para a realização de estudos no exterior: 
QUADRO 2-MODALIDADES DE FINANCIAMENTO

\begin{tabular}{|l|c|c|}
\hline FINANCIAMENTO & $\boldsymbol{N}$. & $\square \%$ \\
\hline COM BOLSA & 81 & 65,9 \\
SEM BOLSA & 42 & 34,1 \\
\hline
\end{tabular}

FONTE: o autor, a partir de Brasil. Conselho Nacional de Desenvolvimento Científico e Tecnológico (2006).

As agências de fomento brasileiras, CNPq e Capes, são responsáveis por $66,57 \%$ das bolsas. Logo, a expansão dos estudos dos juristas no exterior, no caso brasileiro, insere-se no fenômeno geral de aumento das bolsas (cf. ALMEIDA, 2004). Observa-se que, entre as bolsas estrangeiras, os países que apresentam maior freqüência são Alemanha e Estados Unidos, repercutindo na escolha desses países. Importa notar, também, que a participação de bolsas concedidas por universidades privadas é desproporcional em relação à participação da rede privada na expansão dos cursos de pós-graduação no Brasil.

QUADRO 3 - MODALIDADES DE BOLSAS CONCEDIDAS

\begin{tabular}{|l|c|c|}
\hline FINANCIAMENTO & $\boldsymbol{N}$ & \% \\
\hline Capes & 31 & 38,27 \\
CNPq & 23 & 28,3 \\
$\begin{array}{l}\text { Bolsas de universidades e } \\
\text { institutos estrangeiros* }\end{array}$ & 8 & 9,87 \\
$\begin{array}{l}\text { Eolsas de governos } \\
\text { estrangeiros* }\end{array}$ & 6 & 7,4 \\
Fulbright (Estados Unidos) & 3 & 3,7 \\
Usaid (Estados Unidos) & 2 & 2,46 \\
DAAD (Alemanha) & 2 & 2,46 \\
AVH (Alemanha) & 2 & 2,46 \\
Max Planck (Alemanha) & 2 & 2,46 \\
Bolsas de universidades & 2 & 2,46 \\
privadas brasileiras & & \\
\hline
\end{tabular}

FONTE: o autor, a partir de Brasil. Conselho Nacional de Desenvolvimento Científico e Tecnológico (2006).

NOTA: * Excluídas as bolsas concedidas pelos Estados Unidos e Alemanha.

Quanto aos temas de estudo no exterior, predominam os relacionados ao Direito Internacional. Isso se aplica tanto ao que se pode situar no eixo de estudos "públicos" ou, mais especificamente, relacionados a saberes de Estado, quanto aos voltados ao mundo "privado", ou dos negócios e contratos. Também destacam-se os estudos relacionados às Ciências Criminais e à Filosofia e Teoria do Direito, temas dominados na divisão do trabalho jurídico e cujos autores apresentam, tendencialmente, maior investimento na heteronimização da "Ciência Jurídica”, mobilizando as Ciências Sociais e a Filosofia como recursos para a "crítica" daquela12.

QUADRO 4 - TEMAS ESTUDADOS NO EXTERIOR
\begin{tabular}{|l|c|c|}
\hline TEMA & N. & \%, \\
\hline Dir. Internac. Público, Privado e & 30 & 24,19 \\
Comercial & & \\
Cienc. Criminais e Dir. Penal & 17 & 13,70 \\
Filosofia e Teoria do Direito e do & 17 & 13,70 \\
Estado & & \\
Direito Constitucional, & 15 & 12,09 \\
Administrativo e Tributário & & \\
Direito Privado & 11 & 8,87 \\
Direito Processual & 8 & 6,45 \\
Direitos Humanos & 7 & 5,64 \\
Direito do Trabalho & 4 & 3,22 \\
Direito Ambiental & 4 & 3,22 \\
Sociologia do Direito & 3 & 2,41 \\
História do Direito & 3 & 2,41 \\
Direito Comparado & 2 & 1,61 \\
Integraçẫo européia e & 2 & 1,61 \\
Globalizaçẫo & & \\
Metodol. do ensino jurídico & 1 & 0,80 \\
\hline
\end{tabular}

FONTE: o autor, a partir de Brasil. Conselho Nacional de Desenvolvimento Científico e Tecnológico (2006).

A modalidade predominante de curso no exterior é a do Doutorado, seguida pela do Pós-Doutorado. Em ambas é possível relacionar essa predominância aos programas de bolsas concedidas pelo Brasil. A exceção é o Doutorado "sanduíche”, que tem pouca freqüência entre os casos analisados.

\section{QUADRO 5 - MODALIDADES DE CURSO NO} EXTERIOR

\begin{tabular}{|l|c|c|}
\hline MODALIDADE DE CURSO & $\boldsymbol{N}$. & \% \\
\hline Doutorado & 62 & 45,25 \\
Pós-Doutorado & 49 & 35,76 \\
Mestrado & 10 & 7,29 \\
Especialização & 7 & 5,10 \\
Aperfeiçoamento & 5 & 3,64 \\
Doutorado "Sanduíche" & 3 & 2,18 \\
Graduaçẫo & 1 & 0,72 \\
\hline
\end{tabular}

FONTE: o autor, a partir de Brasil. Conselho Nacional de Desenvolvimento Científico e Tecnológico. Plataforma Lattes. Acesso entre julho e outubro de 2006.

NOTA: os cursos de Mestrado só foram contabilizados quando feitos unicamente, sem posterior Doutorado. O Pós-Doutorado, por outro lado, foi contabilizado independentemente da realização do Doutorado no exterior.

12 Para maior detalhamento sobre a relação entre as disciplinas jurídicas e as origens sociais dos docentes, ver Engelmann (2006). 
V. OS PAÍSES MAIS PROCURADOS E A IMPORTAÇÃO DE MODELOS INSTITUCIONAIS

A análise dos países escolhidos para estudos que apresentam maior freqüência entre os juristas é uma dimensão importante na apreensão das modalidades de importação de modelos institucionais. Pode-se relacionar o país escolhido com a inserção dos agentes no Brasil e, ainda, com a legitimação de seus produtos, assim como seu papel de importadores de tecnologias institucionais ${ }^{13}$. No caso dos juristas, o conjunto apresenta-se predominantemente como uma "elite de Estado", o que compreende tanto a ocupação de postos em instituições estatais, o papel de mediadores entre grupos sociais e o Estado, bem como a adesão a um pensamento de Estado, estreitamente vinculado à própria idéia de Direito e às suas práticas. Em função da conformação histórica do campo jurídico brasileiro, esse modelo institucional está identificado com a tradição européia em que o Estado tem papel preponderante como instância de regulação social.

Nesse sentido, os juristas, como mediadores de modelos institucionais, opõem-se, no espaço de lutas pela definição das perícias de governo e de poder, aos economistas ${ }^{14}$ ou aos especialistas em "gestão"15, que atribuem ao mercado o princípio predominante de regulação social. Essa disputa reflete-se nas escolhas dos cursos de pósgraduação.

No caso dos economistas, predominam, como pólo de formação, os Estados Unidos e a Inglaterra. Para os juristas, outros países apresentam-se como pólos fundamentais, como a França, que aparece com a maior freqüência, a Itália e a Alemanha, embora não se possa descartar a significativa presença dos Estados Unidos. Os países europeus mencionados possuem sistemas jurídi-

\footnotetext{
13 Sobre a construção de variáveis e dimensões de análise que permitam apreender a relação entre a importação de modelos institucionais e as estratégias dos importadores no campo nacional, ver Badie (1992), Badieu e Hermet (1993) e Thiriot (2004).

14 Para um panorama dos recursos e perícias mobilizados pelos economistas para a ocupação de espaços no Estado, ver Loureiro (1997).

15 Para maior detalhamento sobre a institucionalização das escolas de administração no Brasil, ver Vasconcellos (1998).
}

cos mais próximos ao brasileiro, comungando do sistema civil law, em detrimento do sistema common law, americano e inglês ${ }^{16}$. Uma das hipóteses para explicar a presença dos Estados Unidos, a despeito das diferenças históricas de sistemas jurídicos, remete aos incentivos (entre os quais, os programas de bolsas), concedidos por agências desse país, para formar especialistas em reforma de instituições e, dessa maneira, exportar o modelo institucional americano para os países periféricos ${ }^{17}$.

QUADRO 6-PAÍS DE REALIZAÇÃO DOS ESTUDOS

\begin{tabular}{|l|c|c|}
\hline PAís & $\boldsymbol{N}$. & \% \\
\hline França & 27 & 20,9 \\
Itália & 23 & 17,82 \\
Estados Unidos & 21 & 16,27 \\
Alemanha & 19 & 14,72 \\
Espanha & 14 & 10,85 \\
Portugal & 9 & 6,97 \\
Inglaterra & 5 & 3,87 \\
Canadá & 3 & 2,35 \\
Japão & 2 & 1,55 \\
Holanda & 1 & 0.77 \\
Suiça & 1 & 0.77 \\
Bélgica & 1 & 0.77 \\
Paraguai & 1 & 0.77 \\
Argentina & 1 & 0.77 \\
Hungria & 1 & 0.77 \\
Austrália & 1 & 0.77 \\
\hline
\end{tabular}

FONTE: o autor, a partir de Brasil. Conselho Nacional de Desenvolvimento Científico e Tecnológico (2006).

NOTA: foram contabilizados casos em que um mesmo indivíduo realizou estudos em dois países diferentes.

Em uma tentativa de melhor visualizar a relação entre o conjunto de variáveis que cerca a "escolha" do país para a o Doutorado, distribuiu-se os dados por região. Nesse agrupamento, destaca-se a mai-

16 Para maior detalhamento sobre a aproximação entre os sistemas civil law e common law, no caso brasileiro, ver Werneck Vianna (1999).

17 Sobre as iniciativas americanas na América Latina, ver Pillar e Sieder (2001) e Thomé (2000). Especificamente sobre o histórico e o desdobramento do movimento americano Law and Development nas reformas institucionais de países latino-americanos, a partir da década de 1960, ver, além dos dois já citados, Delpeuch (2006). 
or freqüência de estudos nos Estados Unidos na região Sudeste, em detrimento das regiões NorteNordeste e Sul. A presença da Alemanha como ter- ceiro país, em conjunto com a Itália, no Sul pode ser também relacionada aos padrões de imigração desses países encontrados nessa região ${ }^{18}$.

QUADRO 7 - PAÍSES MAIS FREQÜENTES DE REALIZAÇÃO DE ESTUDOS X REGIÃO DO BRASIL

\begin{tabular}{|c|c|c|}
\hline REGIÃO & PAÍSES & PAÍS PREDOHINANTE \\
\hline Norte-Nordeste & $\begin{array}{c}\text { França (5), Portugal (4), Itália } \\
\text { (3),Alemanha (2), } \\
\text { Espanha (2) }\end{array}$ & França, Portugal e Itália \\
\hline Centro-Oeste & EUA (4), Espanha (3), França (2) & Estados Unidos, Espanha e França \\
\hline Sudeste & $\begin{array}{c}\text { França (15), Itália (14), EUA (13), } \\
\text { Alemanha (11), Inglaterra (3), Espanha } \\
\text { (2) Japấo (2) Portugal (2) }\end{array}$ & França, Itália e Estados Unidos \\
\hline Sul & $\begin{array}{c}\text { Espanha (7), Itália (6), Alemanha (4), } \\
\text { França (4), Inglaterra (3), Portugal (3), } \\
\text { EUA (2) }\end{array}$ & Espanha, Itália, França e Alemanha \\
\hline
\end{tabular}

FONTE: o autor, a partir de Brasil. Conselho Nacional de Desenvolvimento Científico e Tecnológico (2006).

NOTA: foram contabilizados casos em que um individuo realizou estudos em dois países diferentes; as regiões Norte e Nordeste, devido ao pequeno número de casos e à existência de casos comuns, foram agrupadas.

\section{EVOLUÇÃO CRONOLÓGICA DOS ESTU- DOS DOS JURISTAS NO EXTERIOR}

O estabelecimento de uma cronologia, a partir da data de conclusão dos estudos no exterior, também permite indicações relevantes: entre os casos analisados, o mais antigo possui curso no exterior concluído em 1950, e o mais recente, em 2006. Para melhor análise dos dados, optou-se pela organização em três séries temporais: a primeira compreende os que concluíram algum curso entre 1950 e 1980 (intervalo de 30 anos), período em que encontram-se 21 casos; o segundo engloba os que concluíram cursos no exterior entre 1981 e 1995 (intervalo de 15 anos), com 38 casos; o terceiro situa os que concluíram entre 1996 e 2006 (intervalo de 10 anos), com 62 casos. A primeira observação é que o maior número de juristas que estudaram no exterior concentra-se no menor intervalo, o dos últimos 10 anos. Além disso, o número de juristas que atuam nos cursos de pós-graduação e que formaram-se no exterior nos últimos 10 anos (62) é superior ao de formados entre 1950 e 1996 (59).

Os países mais procurados no primeiro intervalo também variam em relação aos demais, (nove casos nos Estados Unidos; seis na França; três na Alemanha e Itália; e um na Suíça, Espanha e Japão). Interessa notar o predomínio dos Estados Unidos nesse período, sendo que a maioria dos que estudaram nesse país beneficiou-se de pro- gramas de bolsa americanos, nas décadas de 1960 e 1970. No caso da França, as estadas foram realizadas sem bolsa, à exceção de um caso. No total, houve predomínio de estudos sem bolsa, mas mesmo que eles componham a maioria no período, ressalta-se a importância da concessão de bolsas estrangeiras. Em relação às universidades que acolhem os brasileiros no exterior, não se pode identificar, no caso americano, pólos predominantes. Diferenciadamente, no caso da França, predomina a Universidade de Paris I, com três casos em seis. Os outros três casos relacionam-se a universidades do interior: Toulouse, Lyon e Nancy. É importante considerar a posição das universidades nesses países para compreender os efeitos de correspondência com as instituições brasileiras.

Ainda com relação aos casos analisados nesse intervalo, nove são de juristas com atuação na Universidade de São Paulo (USP), universidade que pode ser considerada o pólo mais central e tradicional no espaço das pós-graduações brasileiras em Direito. Nesse pólo, está concentrada, também, a maior freqüência de estudos na Universidade de Paris I, bem como nas universidades americanas, com cinco casos. Ao observar a atuação profissional paralela à atividade acadêmica,

18 Sobre a relação entre etnia, afinidades lingüísticas e a religião com as escolhas de estudos no exterior, ver o estudo de Coradini (2004). 
para os casos da USP, pode-se ter indícios de grande capital social e político detido pelos casos, o que contribui para explicar a ausência de bolsistas. Entre os docentes da USP, ocorre nos currículos a maior concentração de menções à atuação política, à participação em conselhos internacionais, em câmara de comércio, tribunais internacionais e à detenção de distinções honoríficas concedidas por governos municipais, estaduais ou órgãos do Estado.

Outra observação geral que se pode fazer desses dados é de que não há nenhum jurista com atuação em universidade privada, fenômeno que se evidenciará posteriormente e que, em alguma medida, também pode estar relacionado ao surgimento de outros países como pólos de atração, tais como a Espanha e Portugal, que ocupam um espaço periférico em relação aos Estados Unidos, França e Alemanha na divisão internacional da produção acadêmica. Entre os temas estudados, predomina o Direito Internacional, relacionado especialmente aos saberes de Estado, seguido pelos estudos de Direito Público.

Durante o período compreendido entre 1981 e 1995, encontram-se 38 casos. A distribuição entre os países de "escolha” demonstra o predomínio da França e da Itália (11 estudaram na França, nove na Itália, seis na Alemanha quatro na Espanha, três na Inglaterra, dois nos EUA e um caso no Japão, na Bélgica e na Austrália). Há uma diminuição das estadas nos Estados Unidos e o aparecimento da Espanha e da Itália como pólos importantes, tendência que intensifica-se no próximo intervalo.

Com bolsas estrangeiras, aparecem seis casos, contra 12 sem bolsa, e 19 com bolsa Capes ou CNPq. Observa-se, para o período, que os bolsistas representam a maioria, sendo importante ressaltar a predominância de bolsas de agências de fomento brasileiras, o que parece estar associado à expansão dos estudos no exterior. Quanto às modalidades dos cursos realizados, há predomínio do Doutorado, o que indica que as estadas curtas no exterior - sem o incentivo de bolsas -, na forma de aperfeiçoamento ou especialização, tornam-se minoritárias.

Entre as instituições que acolhem os juristas, destaca-se a Universita Degli Studi La Sapienza, da Itália, que concentra seis dentre os nove que estudam na Itália. Desses seis, todos estudam Ciências Criminais, tema mais freqüente, juntamen- te com o Direito Internacional, embora haja uma grande diversificação de temas nesse intervalo. Entre os que estudam na França, não ocorre, como no período anterior, a predominância da Universidade de Paris I.

Quanto ao vínculo às instituições universitárias brasileiras, dos 38 casos presentes nesse intervalo, 18 são vinculados a instituições da região sudeste, que concentra a maioria dos juristas que estudaram fora do país durante o período, sendo que São Paulo é o estado mais representado. Na região sul, situam-se nove casos; na região nordeste, seis, distribuídos entre Paraíba, Pernambuco e Rio Grande do Norte; no centrooeste, ocorrem três casos, todos vinculados à instituições de Brasília, Universidade de Brasília (UnB) e Universidade Católica de Brasília (UCB). Nesse intervalo, aparecem também os primeiros casos de professores atuando em pós-graduações de universidades privadas, embora ainda predomine, amplamente, a atuação em universidades públicas.

Observa-se que a USP possui, como no intervalo anterior, o maior número de juristas com estudos no exterior, muito embora concentre o menor número deles com estudos financiados com bolsas. Dos 13 casos, apenas três têm bolsa de agência brasileira (Capes); quatro, de governos estrangeiros; e os demais não possuem nenhuma bolsa. Da mesma forma, observa-se, para os casos da USP, uma maior inserção em carreiras jurídicas tradicionais, em detrimento da dedicação exclusiva às atividades acadêmicas. Entre essas carreiras, predomina a participação em diversos conselhos profissionais e órgãos públicos, além da advocacia como atividade principal, tal como observado no intervalo anterior. O caso da USP pode ser contrastado com o da região sul, em que apenas dois exercem outra atividade, além da de professor, e em que todos são bolsistas, com apenas um (do Paraná) de uma instituição estrangeira.

Finalmente, no terceiro intervalo de tempo (1996-2006), encontra-se o maior número de docentes com passagem pelo exterior (62), indicando que a maioria dos juristas que atuaram na pósgraduação, em 2006, realizaram estudos fora do país, durante os últimos dez anos. Nesse intervalo, surge também uma diversificação dos países onde realizaram-se os estudos, com o aparecimento, inclusive, de países da América Latina, como Argentina e Paraguai, em dois casos. O predomínio é de países da Europa (Itália, 13; Alemanha, 
10; Portugal e Espanha, com nove cada; França, oito; Grécia, Holanda, Hungria e Inglaterra, com um caso cada). Os Estados Unidos aparecem com oito casos e o Canadá, com dois. Percebe-se, portanto, que países mais centrais e predominantes nos outros intervalos analisados perderam espaço para Itália, Portugal e Espanha; a exceção é a Alemanha, que permanece entre os países com maior freqüência em todos os intervalos.

A diversificação e expansão dos estudos no exterior parece estar diretamente relacionada à expansão das bolsas concedidas por agências brasileiras. Dos 62 casos analisados, 33 são de bolsistas de agências de fomento nacionais (22 da Capes, nove do CNPq e um da Fapesp) e 12 de agências estrangeiras. Há também três casos que declaram bolsa de universidades privadas - Universidade do Vale do Rio dos Sinos (Unisinos), do Rio Grande do Sul, e Pontifícia Universidade Católica de Minas Gerais (PUC-MG) - e, finalmente, um caso com bolsa concedida pelo Ministério Público do Estado de São Paulo. Esses casos representam $80 \%$ dos que receberam algum tipo de bolsa para estudar no exterior.

As estadas sem bolsa concentram-se nos estudos na Espanha, Itália e Portugal, justamente os países que apresentam grande freqüência nesse intervalo. Dos 17 casos que declaram não ter bolsa, dez possuem cargo público de magistrado ou procurador, carreiras que possibilitam, principalmente a partir da década de 1990, licenças com remuneração para estudos no exterior. Nesses casos, acumulam-se o exercício das carreiras jurídicas e o magistério, predominantemente em instituições universitárias federais (apenas seis, dentre os casos mencionados, são professores de instituições privadas). Tais fatos ilustram os investimentos, em estudos fora do país, até mesmo dos agentes e instituições do campo jurídico "prático".

Quanto à modalidade de curso, dos 62 analisados, 27 realizaram Doutorado - e alguns também Pós-Doutorado; 24 declaram ter realizado somente o Pós-Doutorado no exterior, sendo que seis deles sem bolsa - majoritariamente, membros de carreiras de Estado; no caso dos 27 que realizaram Doutorado, 14 tiveram bolsa. Nota-se a pouca freqüência do Doutorado na modalidade "sanduíche", presente em apenas dois casos. Também os cursos de Aperfeiçoamento, Especialização e Mestrado são menos freqüentes do que nos intervalos anteriores.
Há maior diversificação dos temas de estudo, mas ainda predomina o Direito Internacional. Temas de Filosofia do Direito, Teoria do Direito e Sociologia do Direito aparecem com freqüência maior do que anteriormente. Entre os que estudam temas mais “teóricos”, apenas dois exercem outra profissão além de docente. Também aparecem com grande freqüência temas relacionados ao Direito Penal e às Ciências Criminais. O Direito Processual é o que apresenta maior relação com o pertencimento a profissões práticas.

A diversificação e a expansão do sistema de pós-graduação no Brasil refletem-se nesse intervalo. Pela primeira vez, aparecem instituições da região norte - com cinco casos que atuam no Amazonas, sendo dois comuns com São Paulo. A área predominante de estudos é o Direito Ambiental. No nordeste, situam-se cinco casos; no centro-oeste, quatro, todos da Universidade Católica de Brasília (UCB) e da UnB; a região sudeste apresenta 18 docentes com formação no exterior: a PUC-MG e a Universidade Federal de Minas Gerais apresentam sete, Rio de Janeiro, três, e São Paulo, oito, sendo dois comuns com o Amazonas. A USP, que liderava nos intervalos anteriores, agora é minoritária no sudeste. A região sul apresenta 29 docentes, ficando na frente das demais. Há, contudo, uma sobre-representação do Paraná, com 14 docentes da Universidade Federal do Paraná tendo realizado Pós-Doutorado no exterior.

Ao relacionar a presença em universidades públicas e privadas, observa-se que, dos 62 casos, 24 são professores de universidades privadas $(37,5 \%)$. Esse número é significativo em relação aos períodos anteriores e indica a presença do ensino privado de pós-graduação em Direito na absorção de uma parte significativa da geração mais recente de juristas que estudaram no exterior. Contudo, essa fração ainda é minoritária, considerando-se o número de cursos de pós-graduação privados em relação aos públicos, nas regiões sudeste e sul.

Entre os que exercem outra profissão, além da de professor, dez declaram ser advogados, geralmente de forma concomitante com a atividade em universidades privadas; oito exercem a magistratura, sendo todos professores de universidade pública; sete detém o cargo de Procurador em órgãos governamentais municipais, estaduais ou federais; seis são promotores públicos ou pro- 
curadores de Justiça (segundo grau da carreira de Promotor) - entre esses casos, concentra-se o maior número de estudos no exterior sem bolsa, majoritariamente em cursos de Pós-Doutorado, sendo que, no caso dos magistrados, a maioria realizou Doutorado.

Agrupando comparativamente os intervalos analisados, pode-se obter o seguinte quadro sintético:

QUADRO 8 - SÍNTESE DOS DADOS, AGRUPADOS CRONOLOGICAMENTE

\begin{tabular}{|c|c|c|c|}
\hline INTERVALO & $1950-1980$ & 1981-1995 & 1996-2006 \\
\hline Número de casos & 21 & 38 & 62 \\
\hline $\begin{array}{l}\text { Países } \\
\text { predominantes }\end{array}$ & $\begin{array}{l}\text { EUA, França, } \\
\text { Alemanha }\end{array}$ & $\begin{array}{l}\text { França, Itália, } \\
\text { Alemanha }\end{array}$ & $\begin{array}{l}\text { Itália, Alemanha, Espanha, } \\
\text { Portugal }\end{array}$ \\
\hline Universidades* & Paris I (F rança) & La Sapienza (Itália) & $\begin{array}{c}\text { Diversificado } \\
\text { Un. Degli Studi Di Milano } \\
\text { (Itália) }\end{array}$ \\
\hline Inst. Atuação Brasil & USP & Regiẫo Sudeste & Regiẫo Sul (UFPR) \\
\hline $\begin{array}{l}\text { Modalidade de } \\
\text { estudo }\end{array}$ & $\begin{array}{l}60 \% \text { Doutorado } \\
40 \% \text { Mestrado e } \\
\text { Especializaçấo }\end{array}$ & $\begin{array}{c}66 \% \text { Doutorado } \\
18 \% \text { Pós-Dout. } \\
16 \% \text { Mestrado, Esp. } \\
\text { ou Aperfeiç oamento }\end{array}$ & $\begin{array}{c}44 \% \text { Doutorado } \\
39 \% \text { Pós-Doutorado } \\
3 \% \text { Dout. "sanduíche" } \\
14 \% \text { Mestrado ou } \\
\text { Aperfeiçoamento. }\end{array}$ \\
\hline Temas de estudo & $\begin{array}{l}\text { Direito Internacional, } \\
\text { Direito Público }\end{array}$ & $\begin{array}{l}\text { Direito Internacional, } \\
\text { Ciềncias Criminais }\end{array}$ & $\begin{array}{c}\text { Dir. Internacional, Ciências } \\
\text { Criminais, Teoria e F ilosofia } \\
\text { do Direito }\end{array}$ \\
\hline Bolsa & $\begin{array}{c}20 \% \text { bolsas brasileiras } \\
30 \% \text { bolsas } \\
\text { estrangeiras } \\
50 \% \text { sem bolsa }\end{array}$ & $\begin{array}{c}52 \% \text { bolsas brasileiras } \\
16 \% \text { bolsas } \\
\text { estrangeiras } \\
32 \% \text { sem bolsa }\end{array}$ & $\begin{array}{c}53 \% \text { bolsas brasileiras } \\
20 \% \text { bolsas estrangeiras } \\
5 \% \text { bolsas universidades. } \\
\text { privadas } \\
2 \% \text { bolsas Ministério Público } \\
\text { de Sẫo Paul } \\
20 \% \text { sem bolsa }\end{array}$ \\
\hline $\begin{array}{l}\text { Atuação profissional } \\
\text { predominante }\end{array}$ & $\begin{array}{l}75 \% \text { advogados } \\
25 \% \text { carreira } \\
\text { acadêmica }\end{array}$ & $\begin{array}{c}48 \% \text { carreira } \\
\text { acadêmica } \\
\text { (universidades } \\
\text { privadas) } \\
40 \% \text { advogados } \\
12 \% \text { sem precisấo }\end{array}$ & $\begin{array}{c}16 \% \text { advogados } \\
13 \% \text { magistrados } \\
11 \% \text { procuradores de } \\
\text { estadosiprefeiturasiUniẫo } \\
10 \% \text { promotores ou } \\
\text { procuradores de Justiça } \\
50 \% \text { c arreira acadêmica }\end{array}$ \\
\hline
\end{tabular}

FONTE: o autor, a partir de Brasil. Conselho Nacional de Desenvolvimento Científico e Tecnológico (2006).

NOTA: * Universidades com mais de três citações.

\section{CONSIDERAÇÕES FINAIS}

Como primeira conclusão do agrupamento de informações apresentado, pode-se mencionar $o$ crescimento da escolha de países menos centrais para a realização de cursos no exterior, tais como Espanha, Portugal e Itália. Em contrapartida, a Alemanha mantém-se constante, ao contrário da influência dos Estados Unidos e da França, que diminui.

Quanto às universidades estrangeiras, há grande diversificação, com uma tendência - que necessita ser melhor estudada - de formação de pólos localizados, na Itália e Espanha. Essa diversificação também concerne às instituições de atuação dos docentes no Brasil, com a presença da rede de ensino privada e das regiões norte e nordeste.

A inserção, no Brasil, dos professores de Direito que estudaram no exterior é, predominantemente, na carreira acadêmica, mas com uma atuação que combina a presença em universidades públicas e privadas ou em diversas universidades privadas. A docência nas privadas está de acordo com um padrão de expansão da pós-graduação em Direito - e em "Ciências Sociais Aplicadas", 
em geral -, que ocorre, diversamente de outros campos profissionais, por meio da iniciativa privada. Mesmo assim, em termos absolutos, constata-se, entre as universidades públicas, o predomínio de estudos no exterior.

Outro aspecto importante a ser considerado diz respeito à inserção desses juristas nas carreiras de Estado. No período posterior a 1996, ocorre maior freqüência desses segmentos entre os que estudaram no exterior. Nesses casos, predominam incentivos, relacionados às próprias carreiras, para cursos mais longos ou Pós-Doutorados. Os países de escolha concentram-se entre Portugal, Espanha e Itália, o que pode estar relacionado de forma bastante forte às tomadas de posição sobre concepções e modelos de Estado. Tais tomadas de posição aparecem de forma mais nítida nos confrontos protagonizados, no debate público, com outros segmentos profissionais, cujos pólos principais de formação estão relacionados a países em que predominam outros modelos institucionais, mais centrados no mercado como princípio de regulação social.

Os investimentos nesses países, num quadro de diversificação dos estudos no exterior, também podem ser relacionados às maiores facilidades de intercâmbio, tendo em vista proximidades lingüísticas e, mesmo, em alguns casos, menor dificuldade de ingresso e menos exigências para a obtenção de títulos.

Fabiano Engelmann (fabengel@pq.cnpq.br) é Doutor em Ciências Sociais pela École des Hautes Études en Sciences Sociales (EHESS) e Professor do Programa de Mestrado e Doutorado em Ciência Política da Universidade Federal de São Carlos (UFSCAR).

\section{REFERÊNCIAS BIBLIOGRÁFICAS}

ADORNO, S. 1988. Os aprendizes do poder. Rio de Janeiro : Paz e Terra.

ALMEIDA, A. M. 2004. Circulação internacional e formação das elites brasileiras. Campinas : UNICAMP.

BADIE, B. 1992. L'État importe : l'occidentalisation de l'ordre politique. Paris : Fayard.

BADIE, B. \& HERMET, G. 1993. Politica comparada. Ciudad de México : Fondo de Cultura Económica.

BOURDIEU, P. 1986. La force du Droit : éléments pour une Sociologie du Champ Juridique. Actes de la Recherche en Sciences Sociales, Paris, v. 64, p. 3-19, sept.

2002. Les conditions sociales de la circulation internationale. Actes de la Recherche en Sciences Sociales, Paris, v. 145, p. 3-8, déc.

CARVALHO, J. M. 1996. A construção da ordem : a elite política imperial. Teatro de sombras : a política imperial. $2^{\mathrm{a}}$ ed. Rio de Janeiro : Relume-Dumará.

CHARLE, C. 2001. La crise des societés imperiales : Allemagne, France, GrandeBretagne 1900-1940. Paris : Seuil.
CORADINI, O. L. 2004. Formação e inserção profissional dos professores de Ciências Humanas e Sociais no Rio Grande do Sul. In : ALMEIDA, A. M. (org.). Circulação internacional e formação das elites brasileiras. Campinas : UNICAMP.

DELPEUCH, T. 2006. La cooperation internationale au prisme du courant de recherche « droit et développement ». Droit et Societé, Paris, n. 62, p. 36-52.

DEZALAY, Y. 1992. Marchand de Droit. Paris : Fayard.

1993. La production doctrinale comme objet et terrain de luttes politiques et professionnelles. In : POIRMEUR, Y. (org.). La doctrine juridique. Paris : PUF.

1999. O big bang e o Direito : internacionalização e reestruturação do espaço legal. In : FEATHERSTONE, M. (org.). Cultura global : nacionalismo, globalização e modernidade. Petrópolis : Vozes.

DEZALAY, Y. \& GARTH, B. 2002. The Internationalization of Palace Wars : Lawyers, Economists and the Contest to Transform Latin American States. Chicago : University of Chicago. 
ENGELMANN, F. 2006a. Sociologia do campo jurídico : juristas e usos do Direito. Porto Alegre : S. A. Fabris.

2006b. Internacionalismo e ativismo judicial : as causas coletivas. Lua Nova, São Paulo, n. 69, p. 123-146.

2007. Diversification de l'espace juridique et invention de la « critique du droit » au Brésil dans les années 1990. Droit et societé, Paris, n. 65.

GAUER, R. M. 2001. A construção do Estadonação no Brasil : a contribuição dos egressos de Coimbra. Curitiba : Juruá.

HAMMAN, P. (org.). 2002. Discours savants, discours militants : mélange de genres. Paris : Harmattan.

LOUREIRO, M. R. 1997. Os economistas no governo. Rio de Janeiro : FGV.

MEILI, S. 2001. Latin American CauseLawyering Networks. In : SARAT, A. \& SCHEINGOLD, S. (eds.). Cause-Lawyering in the State in a Global Era. New York : Oxford University.
PILAR, D. \& SIEDER, R. 2001. Rule of Law in Latin America : The International Promotion of Judicial Reforms. London : University of London.

SARAT, A. \& SCHEINGOLD, S. 2006. Cause Lawyers and Social Movements. Stanford : Stanford University.

THOME, J. R. 2000. Heading South But Looking North : Globalization and Law Reform in Latin America. Wisconsin Law Review, n. 3, p. 691712, Fall.

THIRIOT, C. (org.). 2004. Penser la politique comparée : un état des savoirs théoriques et méthodologiques. Paris : Karthala.

VASCONCELLOS, M. D. 1998 L'internationalisation des écoles de gestion au Brésil. Actes de la recherche en sciences sociales, Paris, v. 121-122, p. 8-14, mars.

VENÂNCIO FILHO, A. 1977. Das arcadas ao bacharelismo : 150 anos de ensino jurídico no Brasil. São Paulo : Perspectiva.

WERNECK VIANNA, L. (org.). 1999. A judicialização da política e das relações sociais no Brasil. Rio de Janeiro : Revan.

\section{OUTRAFONTE}

BRASIL. CONSELHO NACIONAL DE DESENVOLVIMENTO CIENTÍFICO E TECNOLÓGICO. Plataforma Lattes. Disponível em : http://lattes.cnpq.br/. Acesso em : 31.out.2006.

BRASIL. COORDENAÇÃO DE APERFEIÇOAMENTO DE PESSOAL DE NÍVEL SUPERIOR. 2006. Bolsas no exterior. Disponível em : http://www.capes.gov.br/bolsas/bolsas-no- exterior. Acesso em : 15.out.2006.

CRBC. 2007. Catalogue général des thèses françaises sur le Brésil en sciences humaines et sociales (1823 -2007). Paris : Centre de Recherches sur le Brésil Contemporain. Disponível em : http://www.ehess.fr/crbc/cbcthes/sommaire.html\#sommaire. Acesso em : 22.set.2008. 


\section{Fabiano Engelmann}

ABSTRACT: The present text analyzes study abroad on the part of professors who teach in Master's and Doctoral programs in Brazil, using information provided through the national curriculum bank, or Plataforma Lattes, maintained by the National Council for Scientific and Technological Development ( Conselho Nacional de Desenvolvimento Científico e Tecnológico (CNPq)) , for the year of 2006. This data is analyzed within the context of a discussion on the effects of the internationalization of experts in State management and the uses of "Applied Social Sciences", since the use of such expertise is related to the strategies mobilized by agents in disputes over positions of power and around definitions of "the State", "politics" and "justice". This enables us to elaborate hypotheses on the relationship between the international circulation of Brazilian jurists and the import and export of institutional models, as well as their repercussions within national juridical and political space. The reconverting of agents previously devoted mainly to the 'operational world' toward an academic career and intellectual production, through investment in doctoral degrees and studies abroad, may be analyzed as the search to internationalize and provide new bases for knowledge related to the State and management of political and juridical institutions Similarly, in the case of jurists, this process includes the intellectual bases for resistance to institututional models that identify a weakening of the premises of the Nation-state.

KEYWORDS: study abroad; institutional mediation; juridical space; juridical elites; international circulation of elites.

\section{ÉTUDES À L'ÉTRANGER ET MÉDIATION DE MODÈLES INSTITUTIONNELS : LE CAS DES JURISTES BRÉSILIENS}

\section{Fabiano Engelmann}

Le présent texte est une analyse du profil des études à l'étranger - diplômes master et doctorat - des professeurs de Droit au Brésil, à partir des informations qu'ils ont fournies pour le registre de leur curriculum vitae dans la Plateforme Lattes, du Conseil National de Développement Scientifique et Technologique-CNPq, en 2006. Ces données sont analysées dans le contexte d'une discussion sur les effets de l'internationalisation des expertises de gestions de l'État et des usages des « Sciences Sociales Appliquées », puisque l'utilisation de ces expertises est liée aux stratégies employées par les agents dans les disputes pour les positions de pouvoir et pour la définition du sens d' "État ", « politique » et « justice ». Ainsi, sont effectuées des hypothèses sur la relation entre la circulation internationale de juristes brésiliens et les mouvements d'importation et exportation de modèles institutionnels, ainsi que de leurs influences dans l'espace juridique et politique nationaux. Les reconversions d'agents - qui se consacraient jusqu'alors surtout au « monde opérationnel » - vers la carrière académique et la production intellectuelle, en investissant dans les titres de docteur et dans les études à l'étranger, peuvent être analysées dans un rapport étroit avec la demande par la refondamentation et l'internationalisation des connaissances liées à l'État et à la gestion des institutions politiques et juridiques. De même, ce processus, dans le cas des juristes, regarde la fondamentation intellecutelle de la résistance aux modèles institutionnels, révélateurs de l'affaiblissement des principes de l'État-nation.

MOTS-CLÉS : études à l'étranger ; médiation institutionnelle ; espace juridique ; élites juridiques ; circulation internationale d'élites. 